\title{
The effect of IPS-modified, an early intervention for people with mood and anxiety disorders: study protocol for a randomised clinical superiority trial
}

\author{
Lone Hellström ${ }^{1 *}$, Per Bech², Merete Nordentoft ${ }^{1}$, Jane Lindschou ${ }^{3}$ and Lene Falgaard Eplov ${ }^{1}$
}

\begin{abstract}
Background: Anxiety and affective disorders can be disabling and have a major impact on the ability to work. In Denmark, people with a mental disorder, and mainly non-psychotic disorders, represent a substantial and increasing part of those receiving disability pensions. Previous studies have indicated that Individual Placement and Support (IPS) has a positive effect on employment when provided to people with severe mental illness. This modified IPS intervention is aimed at supporting people with recently diagnosed anxiety or affective disorders in regaining their ability to work and facilitate their return to work or education.
\end{abstract}

Aim: To investigate whether an early modified IPS intervention has an effect on employment and education when provided to people with recently diagnosed anxiety or affective disorders in a Danish context.

Methods/Design: The trial is a randomised, assessor-blinded, clinical superiority trial of an early modified IPS intervention in addition to treatment-as-usual compared to treatment-as-usual alone for 324 participants diagnosed with an affective disorder or anxiety disorder living in the Capital Region of Denmark. The primary outcome is competitive employment or education at 24 months. Secondary outcomes are days of competitive employment or education, illness symptoms and level of functioning including quality of life at follow-up 12 and 24 months after baseline.

Discussion: If the modified IPS intervention is shown to be superior to treatment-as-usual, a larger number of disability pensions can probably be avoided and long-term sickness absences reduced, with major benefits to society and patients. This trial will add to the evidence of how best to support people's return to employment or education after a psychiatric disorder.

Trial registration: NCT01721824

Keywords: Supported employment, Affective disorder, Anxiety, Competitive employment, Mentor support

\section{Background}

Anxiety and affective disorders are often associated with functional disability and can have a major impact on the ability to work [1-4]. Through the 1990s, depression alone was responsible for an annual loss of US\$ 17 billion due to work absenteeism and a total cost of US\$ 43.7 billion (34.8 billion Euro) each year in direct and indirect

\footnotetext{
* Correspondence: Ione.hellstroem@regionh.dk

${ }^{1}$ Copenhagen University Hospital, Research Unit, Mental Health Centre Copenhagen, Bispebjerg Bakke 23, DK-2400 Copenhagen, Denmark

Full list of author information is available at the end of the article
}

societal costs in the USA [4]. In Denmark, mental health problems account for a total of 7.3 billion Euro each year in direct and indirect societal costs [5]. Disability pension and long-term sickness absence account for the majority $[5,6]$. A significant amount of the total sickness absence in Denmark is due to mental illness, and disability pensions are increasingly awarded due to non-psychotic mental illness [6,7]. Hence it is crucial to start initiatives to support patients with mental health problems in retaining or regaining their employment or education. 
The Individual Placement and Support (IPS)-modified, early intervention for people with mood and anxiety disorder (IPS-MA) is an individualised supported employment intervention, aiming at supporting people with recently diagnosed anxiety or affective disorders to obtain and sustain competitive employment through mentor support. It was created in 2011, based on the experience of a 1-year pilot study, aspects from the supported employment intervention IPS and findings from the literature. The method has never been investigated in a clinical trial.

A recent systematic review of randomised trials as well as controlled non-randomised cohort studies [8] found an overall lack of evidence concerning vocational rehabilitation for patients with recently diagnosed bipolar disorders, depression or anxiety disorders, but points to three important initiatives to consider: preventive interventions, return-to-work interventions and interventions concerning short- or long-term loss of employment. Preventive interventions have only been investigated for patients with depression or depressive symptoms, and show evidence in favour of individualised interventions [9-11]. Considering return to work interventions, studies suggest that an individual intervention should be combined with work-place interventions in close collaboration with mental health services $[4,12,13]$. Returning to work when diagnosed with depression, anxiety or bipolar disorders is also affected by personal and social factors; hence, it is important to incorporate interventions supporting these matters.

Today, vocational rehabilitation mainly consists of two different approaches: pre-vocational training, often referred to as the train-and-place model, and supported employment, referred to as place-and-train [14]. With pre-vocational training, people are trained in company internship programmes, sheltered workshops or wagesubsidised jobs before obtaining competitive employment. Supported employment aims at a rapid search for competitive employment, with on-going support after employment. In Denmark pre-vocational training is still standard.

The most intensively studied supported employment intervention is IPS $[15,16]$, where job consultants are integrated in and act in close collaboration with the mental health services. Several randomised trials [14,17-27] have indicated that IPS is more effective in helping patients with severe mental illness obtain and sustain competitive employment compared to traditional pre-vocational training. A meta-analysis [28] of four randomised trials [29-32] found that, after 18 months, 70.4\% had obtained competitive employment in the IPS group compared to $24.3 \%$ in the control group. In a review including 11 randomised trials comparing IPS to traditional pre-vocational training, $61 \%$ of the patients obtained competitive employment in the IPS group versus $23 \%$ in the control group [15]. No studies were found investigating the effect of IPS when provided to people with recently diagnosed affective or anxiety disorder. It is recommended that the intervention be modified and accommodated to psychosocial and medical aspects, and thoroughly investigated in order to show an effect when offered to, for instance, patients with recently diagnosed anxiety or affective disorders [16]. Further studies are needed in order to investigate the effect of such interventions, in addition to mental health treatment, on people's return to work.

Sherpa ran the pilot study, from October 2010 to September 2011 (unpublished data), during which 46 patients with depression, anxiety or a bipolar disorder were referred to Sherpa from two mental health centres in Copenhagen. Two mentors and a career counsellor were employed at the time. Twenty of the participating patients had obtained either employment or education after a median of 4.2 months (range 1 to 8 months).

The above-mentioned findings from the literature, aspects from the IPS, and the experiences from the 1-year pilot study led to the creation of IPS-MA in 2011.

The IPS-MA is an individualised supported employment intervention, considering personal and social factors, as well as career counselling and financial guidance. Focus is on a rapid search for competitive employment or education, and not sheltered workshops or long internship programmes. Since people with affective disorders or anxiety are treated by either their general practitioner, psychiatric private practitioner or in mental health centres in Denmark, it is difficult to integrate IPS-MA with treatment to the same extend as in IPS. According to IPS-MA, mentors must have an assertive approach to mental health carers and social workers, and collaborate with mental health services as well as job centres and municipalities, and thereby help coordinate services provided by these.

This is the first trial comparing the effect of IPS-MA to treatment-as-usual when provided to people with recently diagnosed anxiety or affective disorders. The hypothesis is that more people receiving IPS-MA will return to work or education compared to the control group.

\section{Methods}

\section{Design}

The Sherpa trial is a randomised, assessor-blinded, clinical superiority trial comparing IPS-MA in addition to treatment-as-usual with treatment-as-usual alone in 324 patients recently diagnosed with an affective disorder or an anxiety disorder (Figure 1).

\section{Participants}

Participants will be recruited from Mental Health Centres and private practising psychiatrists within the Capital Region of Denmark from 1 October 2011 until 31 January 2014. Inpatients as well as outpatients are eligible. 


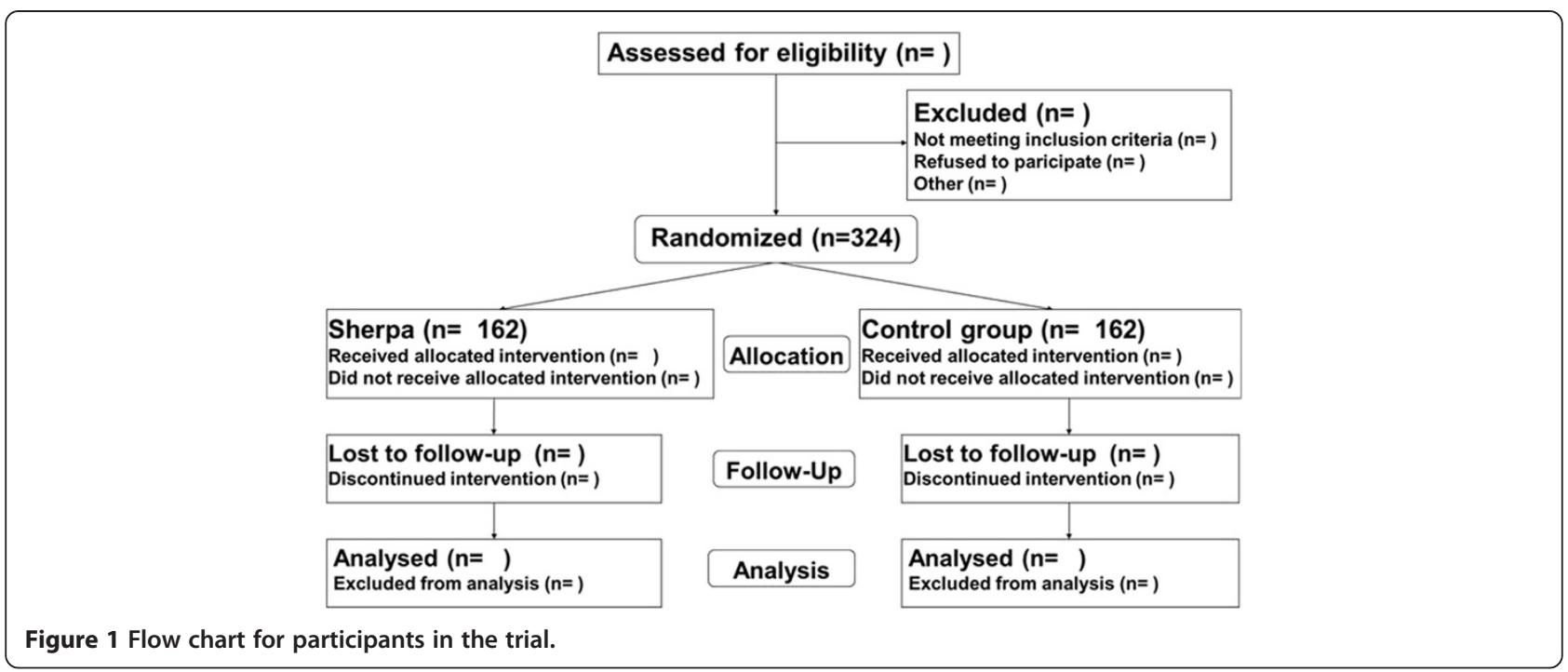

\section{Inclusion criteria}

Participants must be aged 18 to 60 years, diagnosed by the referring psychiatrists according to the International Classification of Diseases 10th edition criteria of affective disorders (F30-39) or anxiety disorders (F40-41), and not have had contact with mental health services for more than 3 years. They must have been employed or enrolled in education at some time during the past 2 years. They must have a pronounced wish to return to either employment or education, but not being ready to do so within the following 3 months, and equal to 'match group' 2 or 3. ('Match groups' are categories used by the job centres in Denmark [33] to estimate how far people are from the labour market. Match group 2 refers to people who can participate in pre-vocational training or courses, but who would not be able to take an ordinary job and be off social benefits within 3 months. Match group 3 refers to people with problems so severe that they cannot work or participate in prevocational training). Participants must have the ability to read and understand Danish, and give informed consent verbally and in writing.

\section{Exclusion criteria}

Participants will be excluded if they have somatic comorbidity causing reduced ability to work, primary large-scale alcohol or substance abuse, a legal guardian, forensic psychiatric arrangements, or if they do not give informed consent.

\section{Recruitment and randomisation}

Eligible patients are informed about Sherpa, given the written information, and subsequently referred to Sherpa by their psychiatrists, nurse or social worker. A Sherpa employee calls the patient to make an appointment for inclusion and baseline interview. The assessor will interview the participants, but a Sherpa mentor will always attend the interview in order to manage the randomisation after the assessor has left and inform the participant about allocation. When a participant is included in the trial, central randomisation is performed when the Sherpa mentor calls the Copenhagen Trial Unit and gives the relevant participant information.

Randomisation is performed according to a computergenerated allocation sequence with a varying block size concealed from the investigators. The randomisation is stratified by a) four diagnoses (F31: Bipolar affective disorder; F30, F32-39: Affective disorders; F40: Phobic anxiety disorders; or F41: Other anxiety disorders), and b) two match groups (match group 2 or 3 ).

\section{Blinding}

It is not possible to blind the participants, the Sherpa mentors, or career counsellors, practitioners and carers who deliver the intervention. However, they are strongly urged not to reveal the allocation to the rest of the research team. The assessor and research team will be blinded to the allocated intervention group throughout the entire trial period. Should blinding be violated, a second assessor will complete the follow-up interview. Furthermore, during statistical analyses, the two intervention groups will be coded as, for example, $\mathrm{X}$ and $\mathrm{Y}$, and the code will not be broken until the research team has drawn two conclusions; one assuming $\mathrm{X}$ is the intervention group and $\mathrm{Y}$ is the control group, and one conclusion assuming the opposite.

\section{Interventions}

\section{The experimental intervention}

Participants randomised to the Sherpa group will be offered IPS-MA in addition to treatment-as-usual (see description for the control group). A Danish protocol describing the 
IPS-MA method can be acquired by contacting the corresponding author. An English version is under construction. The IPS-MA method is based on eight principles: 1) Sherpa is the patient's advocate, not an authority or a healthcare provider; 2) the process is led by the individual's goals and focus is on patient resources; 3 ) assistance is flexible, without time limits, and responsive to the needs of the patient; 4) the goal is competitive employment or education, without pre-vocational training; 5) the belief is that returning to work is possible despite a mental illness, but therapeutic recommendations in terms of postponement are acknowledged; 6) liaison with healthcare and social workers ensures a coordinated service; 7) a meaningful and realistic career plan will be developed and evaluated continuously after job start; and 8) Sherpa is an interdisciplinary team, which will be reflected in the assistance of each individual.

Five basic services comprise IPS-MA:

1) Individualised mentor support based on psychiatric knowledge. Sherpa mentors all have a background as professionals in mental health services. In cooperation with the participant, the Sherpa mentor helps develop a plan of action in which resources and problems in social life as well as working life are clarified. The Sherpa mentor supports the participant in how to structure and manage everyday life, renew contact with friends and/or family, prepare important meetings and live a healthy everyday life with the disorder. The Sherpa mentors very often act as lay representatives for the participants at meetings at the local job centres or municipalities.

2) Coordination of services provided by Sherpa or external providers. Through their professional skills, Sherpa mentors help avoid lack of coordination and unnecessary waiting time and make sure that all available services are provided. Sherpa mentors have an assertive approach to mental health carers and social workers and thereby ensure that relevant information is distributed between services.

3) Career counselling. Professional career counsellors support participants in creating a realistic match between their competences and the demands of the job market. Participants will be given advice on how to write a curriculum vitae and job applications, on job seeking strategies, and help in practicing job interviews and negotiating employment contracts.

4) Impartial help to clarify private economy is offered by a consultancy firm, the Settlement [34], run by volunteers. The firm consists of two employees and a group of volunteers with professional backgrounds in economics, law and social counselling.

5) Contact with employers to help participants obtain jobs, and keep them.
Participants are provided with a Sherpa mentor who will be their mentor throughout the entire intervention period. The search for job or education will commence as soon as possible. Mentor support will continue for as long as needed after employment or education is started. During the first 6 months, the participant and mentor most often meet once a week for 1 to 1.5 hours on average. After 6 months the number of contacts varies and can be by telephone or email. The number and duration of contacts depend on the needs of the participant. Each mentor has a maximum caseload of 20 participants, half of which have been in Sherpa for more than 6 months.

\section{Sherpa team}

The Sherpa team is an interdisciplinary team, consisting of six mentors and two career counsellors. Sherpa mentors all have solid experience as health professionals in mental health services and include one nurse, two social workers and three occupational therapists. Career counsellors have worked as career counsellors, or with recruitment or human resources in the private business sector. Sherpa mentors and career counsellors work closely together and share offices.

\section{Training and supervision}

Newly appointed Sherpa mentors will have a 1-week introduction to working routines, and will attend a 2-day workshop introducing the IPS-MA method. Mentors with experience in the method will conduct the introduction. Team members are furthermore obliged to participate in annual refresher courses.

Team members will have monthly supervision provided by a trained psychologist.

\section{The control group}

Participants randomised to the control group will receive 'treatment-as-usual' as offered by the job centres in Denmark [35]. Services vary according to match group and the participant's possibilities for social support. Participants receiving sickness benefits must attend their first meeting in the job centre within 8 weeks of sickness leave. Match group 2 participants attend follow-up interviews every 4 weeks, whereas match group 3 participants attend followup interviews every 3 months. Participants on social security will attend job-seeking interviews every 3 months.

Participants under the age of 30 have the right and obligation to participate in pre-vocational training after no more than 13 weeks of unemployment. Prevocational training has to last for at least 6 months. Young participants must not be without some sort of pre-vocational training for more than 4 weeks. Participants over the age of 30 have the right and obligation to participate in pre-vocational training after no more than 9 months of unemployment. 
After an individual evaluation, job centres can offer certain pre-vocational training services: company internship programmes in public or private companies as well as in sheltered workshops, wage subsidy jobs, skill development and guidance, and mentor support (often offered by a colleague who helps the participant adapt to the new workplace regarding norms and social competences). Participants receiving sickness benefits can be provided with gradual return to employment, assistive tools, a personal assistant or reimbursement of sickness benefits to the employer from the first day of sickness leave [35].

\section{Participant withdrawal}

Participants can choose to withdraw from the trial at any time during the intervention period, without it having any consequences for the treatment they will receive, but they will politely be reminded of the importance of their participation. Participants who choose to withdraw from the trial are asked to specify which aspects of the trial they withdraw from: participation in the experimental intervention, participation in the follow-up interviews, use of data collected at central registers, or complete withdrawal including use of already collected data.

\section{Fidelity}

To ensure that the services provided by Sherpa are in concordance with the IPS-MA method, an independent investigator will monitor fidelity to the IPS-MA method twice during the first year of the intervention, and subsequently once every year. Fidelity will be monitored using the IPS-MA Fidelity Scale (unpublished, available through corresponding author) by interviewing participants, mentors, and career counsellors, observing team-meetings and meetings between mentor and participant, as well as examining the individual plans of action and the data management systems used. The IPS-MA Fidelity Scale was developed based on the IPS Fidelity Scale [36]. Core elements important to the IPS-MA method investigated are: caseload, mentors' and career counsellors' roles, interdisciplinary team with group supervision, individualised mentor support, development and evaluation of individual plans of action, coordination of services, providing career and economic counselling, focus on rapid search for ordinary employment or education, no time limitations, and individualised support for the participants and their employers, community-based services, assertive engagement and outreach.

\section{Assessments}

Participants will be interviewed and asked to fill in questionnaires at baseline and at follow-up after 12 and
24 months. At baseline, socio-demographic information on education, income base, marital status, number of children and somatic disease will be collected.

To confirm the diagnosis, the Mini International Neuropsychiatric Interview (MINI) [37] is used at baseline. Baseline interviews will always be face-to-face, most often in the participants' home. Participants will fill in questionnaires at home.

\section{Outcomes}

The primary outcome is competitive employment (including being on rehabilitation benefits, flexible jobs, and wage-subsidised jobs) or education at 24 months. Information about employment and education will be extracted from the DREAM database [38]. The database is administered by The National Labour Market Authority and contains information on employment, sickness leave, and education eligible to state education grant, pre-vocational training, disability pension, social security, and sickness benefits.

Secondary outcomes are: 1) number of days of competitive employment or education; 2) level of symptoms assessed by the Hamilton Depression Scale (HAM-D6) $[39,40]$; 3) level of symptoms assessed by the Hamilton Anxiety Scale (HAM-A6) [39,41]; 4) level of functioning assessed by The Global Assessment of Functioning (GAF) $[39,42,43]$; and 5) level of health-related quality of life by The WHO-Five Well-being Index(WHO-5) [39]. Secondary outcomes are assessed after 12 and 24 months.

Exploratory outcomes are: competitive employment (including being on rehabilitation benefits, flexible jobs and wage subsidy jobs) or education at 12 months, reassignment from Match group 2 or 3 to Match group 1, attending company internship programs in public or private companies as well as in sheltered workshops, and information extracted from the DREAM database. Manic symptoms are assessed by the Bech-Rafaelsen Mania Scale (MAS) $[39,44]$. Social performance regarding four domains (socially useful activities, personal and social relationships, self-care and disturbing and aggressive behaviour) is assessed by The Personal and Social Performance (PSP) $[45,46]$. The Sheehan Disability Scale [47] measures functional level regarding social relationships, work, spare time and family. Health-related quality of life in terms of psychological well-being is assessed by the WHO-5 $[39,48]$ and empowerment by the Empowerment Scale [49]. The Changes Questionnaire [50] will be used to assess how motivated participants are as to seeking employment or education. The Client Satisfaction Questionnaire [51] assesses satisfaction with treatment and the EQ-5D (EuroQol) [52] assesses health-related quality of life. The latter of the two will be used in a future health-related cost-benefit analysis. All 
scales and questionnaires used for measuring outcomes are validated scales $[37,39-47,49-52]$.

\section{Register-based information}

Information on vital status, use of mental health services, both as in- and outpatient, number of days of admission, sickness absence and use of social benefits will be gathered from the DREAM database or the Danish Psychiatric Case Register (DPCR) [53]. DPCR is the patient-registry system used by the mental health services in Denmark; it contains information on all hospital admissions, number and duration, outpatient contacts and deaths.

An overview of all data collected and the source of collection is shown in Table 1.
All data will be handled in accordance with the Danish Data Protection Agency.

\section{Training and inter-rater reliability}

Three assessors conduct the interviews: Britt Reuter Morthorst (BM), Marie Lønberg Hansen (MLH) and LH. BM and LH have a masters in health science, and MLH in public health science. BM has 15 years experience as a nurse in mental health, and is an experienced assessor. Assessors have all received the necessary training in the relevant instruments. All assessors have participated in joint ratings for HAM-D and HAM-A with PB. Regarding the MINI, MAS, PSP and GAF, at least seven joint ratings have been conducted in order to ensure inter-rater reliability.

Table 1 Data collection at baseline and follow-up

\begin{tabular}{|c|c|c|c|c|}
\hline Source of collection & Assessment & Baseline & $\begin{array}{l}12 \text { months } \\
\text { follow-up }\end{array}$ & $\begin{array}{l}24 \text { months } \\
\text { follow-up }\end{array}$ \\
\hline \multirow[t]{6}{*}{ Interview } & Hamilton Depression Scale (HAM-D6) & $x$ & $x$ & $x$ \\
\hline & Hamilton Anxiety Scale (HAM-A6) & $x$ & $x$ & $x$ \\
\hline & Bech-Rafaelsen Mania Scale (MAS) & $x$ & $x$ & $x$ \\
\hline & Personal and Social Perfomance scale (PSP) & $x$ & $x$ & $x$ \\
\hline & Global Assessment of Functioning (GAF) & $x$ & $x$ & $x$ \\
\hline & Suicidal ideation & $x$ & $x$ & $x$ \\
\hline \multirow[t]{6}{*}{ Self report } & Sheehan Disability Scale (SDS) & $x$ & $x$ & $x$ \\
\hline & Quality of life (WHO-5) & $x$ & $x$ & $x$ \\
\hline & Empowerment Scale & $x$ & $x$ & $x$ \\
\hline & Changes Questionnaire & $x$ & $x$ & $x$ \\
\hline & Client Satisfaction Questionnaire (CSQ) & $x$ & $x$ & $x$ \\
\hline & Health-related quality of life EQ-5D (EuroQol) & $x$ & $x$ & $x$ \\
\hline \multirow[t]{5}{*}{ Hospital records } & Number of hospital admissions & & $x$ & $x$ \\
\hline & Length of hospital admissions & & $x$ & $x$ \\
\hline & Use of outpatient services & & $x$ & $x$ \\
\hline & Death (all causes) & & $x$ & $x$ \\
\hline & Suicide & & $x$ & $x$ \\
\hline Dream/interview & Sociodemographic information & $x$ & $x$ & $x$ \\
\hline Dream & Labour market affiliation & $x$ & $x$ & $x$ \\
\hline Dream/interview & Civil status & $x$ & $x$ & $x$ \\
\hline DPCR & First contact with mental health care & $x$ & & \\
\hline Dream/interview & Children & $x$ & $x$ & $x$ \\
\hline Dream/interview & Education & $x$ & $x$ & $x$ \\
\hline Dream/interview & Cohabitation status & $x$ & $x$ & $x$ \\
\hline DPCR & Use of mental health service & & $x$ & $x$ \\
\hline Dream & Number of sick days & & $x$ & $x$ \\
\hline Dream & Use of social benefits & & $x$ & $x$ \\
\hline Self report & Treatment and use of other service from the social and healthcare sector & & $x$ & \\
\hline Self report & Service provided by Sherpa & & $x$ & \\
\hline
\end{tabular}

DPCR, The Danish Psychiatric Case Register. 
For the evaluation of inter-rater reliability the intraclass coefficient was used [54]. The level of significance was a coefficient of 0.70 or higher.

LH has participated in joint HAM-D6 and HAM-A6 rating sessions with $\mathrm{PB}$. In total, 28 joint sessions between PB and LH were evaluated and for HAM-D6 the intra-class coefficient was $0.81(P<0.001)$. Together LH and $\mathrm{BM}$ have seen seven patients in joint training sessions; intra-class correlations were: PSP $=0.92$, GAFFunctioning $=0.84$, GAF-Symptoms $=0.75$.

\section{Power and sample size}

We have been unable to find data on how many people actually return to employment or education with traditional pre-vocational training after anxiety or an affective disorder in either the Danish or the national literature. Therefore, we have leaned towards the findings in OPUS, a programme in which young people with schizophrenia receive early intensive treatment for 24 months. In OPUS it was found that $40 \%$ returned to employment or education versus $32 \%$ in the control group (Merete Nordentoft, personal communication). Based on this knowledge, we conservatively estimate that $30 \%$ will regain employment or education following traditional pre-vocational training.

Across a broad range of studies of severe mental illness and IPS versus traditional pre-vocational training, studies show that approximately $50 \%$ more of the participants in the IPS groups regain employment compared to the control groups [15]. We therefore expect to find that $50 \%$ more of the participants in the Sherpa group compared to the control group will regain employment or education, and have estimated the true difference in the experimental and control group to be 15\%-points; hence, $45 \%$ of the participants in the Sherpa group will regain employment. To be able to reject the null hypothesis that the proportion of participants who regain employment or education in the experimental and control group is equal with a probability (power) of $80 \%, 162$ participants will be required in each group (total 324). The Type I error probability associated with the test of this null hypothesis is $5 \%$. We also estimated the sample size using a power of $90 \%$. This resulted in a total of 434 participants $(2 \times 217)$. We therefore plan to recruit a minimum of 324 participants and, in order to reduce the risk of type II error, we will aim to recruit up to 434 participants, if possible, in the 2-year recruitment period. Power and sample size calculations have been made using the PS Power and Sample Size Calculations program version 3.0.14 [55,56].

The power for the secondary outcomes has been estimated based on a number of 162 participants in each group (Table 2). Since it has not been possible to find studies or trials similar to our trial regarding patient group or method, expected effect size concerning number of days in employment or education has been conservatively estimated. The studies found [1,9,19,21,22,57-59] did not find any difference between groups after 12 months considering GAF-F, WHO-5, HAM-D6 or HAM-A6. If we find a difference between groups, we want it to be clinically relevant; therefore, the effect sizes equals the clinically relevant difference.

\section{Statistical analyses}

Data analyses will be based on the intention-to-treat principle, which means that data will be included in the group to which the participant was randomised, regardless of intervention received. Data will be analysed using the IBM SPSS Statistics version 20 for Windows.

To assess homogeneity of the two groups at baseline, demographic data such as age, gender, marital status, education level, support (social benefits, social security and so forth), diagnosis and Match group at baseline will be presented.

Dichotomous outcomes will be analysed using logistic regression. For primary and secondary outcomes, an unadjusted analysis of the effect of the Sherpa method as an add-on to treatment-as-usual versus exclusively treatment-as-usual will be carried out, as well as an analysis adjusted for stratification variables (diagnosis and Match group). Multiple multivariate imputations will be used to impute a distribution of missing values.

Table 2 Power calculations for secondary outcomes, calculated from a sample size of 324 participants

\begin{tabular}{|c|c|c|c|c|c|}
\hline Measure & Mean difference & $\begin{array}{l}\text { Standard deviation } \\
\text { of the pooled mean }\end{array}$ & $\begin{array}{l}\text { Type I } \\
\text { error }\end{array}$ & Reference & Power \\
\hline $\begin{array}{l}\text { No of days of competitive employment } \\
\text { of education at } 12 \text { months }\end{array}$ & 60 days & 150 days & $5 \%$ & Kin W 2008 [21], Burns 2007 [14] & $95 \%$ \\
\hline GAF-F & 5 & 15 & $5 \%$ & Hoffmann 2011 [19], Howard 2010 [58] & $85 \%$ \\
\hline WHO-5 & 10 & 19 & $5 \%$ & Latimer 2006 [22], Burns 2009 [14] & $99 \%$ \\
\hline HAM-D6 & 2 & 4 & $5 \%$ & $\begin{array}{l}\text { Wang } 2007 \text { [10], Lexis } 2011 \text { [9], } \\
\text { Brouwers } 2006 \text { [1], Van Oostrom } 2010 \text { [59] }\end{array}$ & $99 \%$ \\
\hline HAM-A6 & 2 & 4 & $5 \%$ & $\begin{array}{l}\text { Wang } 2007 \text { [10], Lexis } 2011 \text { [9], } \\
\text { Brouwers } 2006 \text { [1], Van Oostrom } 2010 \text { [59] }\end{array}$ & $99 \%$ \\
\hline
\end{tabular}


Continuous outcomes will be analysed in a mixed model with repeated measurements. This model is based on the assumption that data are missing at random or missing completely at random [60].

\section{Feasibility}

In 2010, 11,712 inpatient visits were registered in the Mental Health Care Centres of the Capital Region of Denmark, not including emergency wards [61]. During the same period of time there were 4,538 first-time psychiatric emergency ward visits in the Capital Region of Denmark [61]. Based on these figures we find it realistic to include a minimum of 324 participants from 1 October 2011 until 31 December 2013.

Each mentor has a maximum caseload of 20 participants per year; six mentors are currently engaged in Sherpa. Thus it is also realistic regarding the capacity of Sherpa mentors to include and complete the intervention for 162 participants in 3 years.

\section{Ethical considerations}

All participants in this trial, randomised to experimental as well as control group, are offered treatment according to best practice. The trial will follow international ethical guidelines of informed consent in clinical trials. Participants will receive written and verbal information about the trial so as to be able to give an informed consent. Consent has to be given verbally and in writing. Participation is voluntary, and participants can withdraw their consent at any time during the trial without it having any consequences for their treatment. Previous trials have not found any risks or adverse reactions to the supported employment intervention $[19,31,62,63]$. If any of the participants present suicidal ideations, the mentor and assessor will make sure that they can be distracted from these thoughts, have a crisis plan, are not alone after the interview and, if in doubt of any of the above, they will offer to follow the participant to the psychiatric emergency ward.

The trial protocol was submitted to the Regional Ethics Committees of the Capital Region for review (journal no: H-2-2011-FSP20). The committee assessed the protocol to be exempt from formal approval, since it is not a biomedical trial. The trial has been reported to the Danish Data Protection Agency (RHP journal no: 2007-58-0015, local journal no: RHP-2011-20) and has been registered at http://www.clinicaltrials.gov identifier: NCT01721824.

\section{Trial status}

The trial is on-going; 290 participants have been randomised, and recruitment continues until 31 January 2014.

\section{Discussion}

The IPS-MA method is based on a 1-year pilot study and the evidence supporting IPS in other countries. To our knowledge this is the first trial investigating the effect of a supported employment intervention when provided to people with a recently diagnosed affective disorder or anxiety disorder, an area with only sparse knowledge about effective interventions. A strength of the study is the centralised computer-based randomisation which ensures an adequate generation of the allocation sequence and adequate allocation concealment. The use of blinded outcome assessors for the primary outcome and the fact that it is a register-based outcome as well as the use of intention-to-treat analysis decreases the risk of biased effect estimates. The trial is registered at http://www.clinicaltrials. gov, which helps preventing selective and incomplete outcome reporting. The primary outcome is register-based, which ensures almost complete follow-up due to the comprehensiveness of Danish registers.

The fact that we monitor fidelity to the IPS-MA method on a yearly basis is another strength of this trial. We do so to ensure that mentors and career counsellors are true to the method.

A limitation to this trial is that we are not able to blind participants, mentors or carers. Some might argue that it is difficult to sustain the blinding of the assessor during follow-up, and this is certainly a risk of bias. Should blinding be violated, a second assessor will complete the follow-up interview.

Even though participants are recruited from mental health centres throughout the Capital Region of Denmark, and should be fairly representative of the population in the region, we may have a reduced external validity. As it is the staff at the mental health centres that identify eligible participants, not everybody with an affective disorder or anxiety disorder eligible might have been asked to participate; patients are not systematically screened for eligibility.

Due to differences in labour markets and well-fare systems, results may not be directly generalisable to other countries.

\section{Impact of the results}

The results of this trial will add to the limited knowledge regarding vocational rehabilitation for people with recently diagnosed anxiety or affective disorders. If potential positive results can be confirmed in other trials, the IPS-MA method can be implemented at the job centres nationwide, and would probably prevent a large number of disability pensions and long-term sickness absences with major benefits to society and patients.

\section{IPS-MACompeting interests}

LH's PhD is exclusively founded by the Obel Family Foundation. Due to administrative convenience, PhD 
student LH was formally employed by Sherpa from 1 June 2011 until 31 August 2013. LH has throughout the entire period been working at the Research Unit at Mental Health Centre Copenhagen, where she is now employed. Managerial responsibility and supervision lie with LFE and PB. Sherpa has had no role in the trial design, and will have no role in collection of data, analysis of data, data interpretation, or in publication of data from the trial. None of the other authors have any competing interest.

\section{Abbreviations}

DPCR: Danish psychiatric case register; GAF: Global assessment of functioning; HAM-A6: Hamilton anxiety scale; HAM-D6: Hamilton depression scale; IPS: Individual placement and support; IPS-MA: IPS-modified, early intervention for people with mood and anxiety disorder; MAS: The Bech-Rafaelsen mania scale; MINI: Mini international neuropsychiatric interview; PSP: Personal and social performance; WHO-5: WHO-Five well-being index.

\section{Competing interests}

The authors declared that they have no competing interests.

\section{Authors' contributions}

LFE conceived the trial, participated in the planning and design, and read and critically revised the manuscript for important intellectual content. LH participated in the planning and design of the trial, conducted the research interviews, drafted the manuscript and, along with LFE, critically revised it for important intellectual content. MN participated in the planning and design of the trial, and has read and critically revised the manuscript. JL participated in the planning and design of the trial, and has read and critically revised the manuscript. PB participated in the planning and design of the trial, was responsible of the training of the assessors, and has read and critically revised the manuscript. All authors read and approved the final version of the manuscript.

\section{Acknowledgements}

Britt Reuter Morthorst and Marie Lønberg Hansen for excellent assistance in recruiting participants, conducting research interviews and data assessment. Ann-Lis Gregersen for, among many other things, patiently contacting participants for follow-up.

\section{Funding}

The trial as a whole is founded by the Obel Family Foundation, the Tryg Foundation, and the National Labour Market Authority. No current or future sponsors of the trial will have any role in the trial design, collection of data, analysis of data, data interpretation, or in publication of data from the trial.

\section{Author details}

'Copenhagen University Hospital, Research Unit, Mental Health Centre Copenhagen, Bispebjerg Bakke 23, DK-2400 Copenhagen, Denmark. ${ }^{2}$ Psychiatric Research Unit, Mental Health Centre North Zealand, Dyrehavevej 48, 3400 Hillerød, Denmark. ${ }^{3}$ Department 3344, Copenhagen Trial Unit, Centre for Clinical Intervention Research, Rigshospitalet, Copenhagen University Hospital, Blegdamsvej 9, DK-2100 Copenhagen $\varnothing$, Denmark.

Received: 28 June 2013 Accepted: 10 December 2013 Published: 24 December 2013

\section{References}

1. Brouwers EP, Tiemens BG, Terluin B, Verhaak PF: Effectiveness of an intervention to reduce sickness absence in patients with emotional distress or minor mental disorders: a randomized controlled effectiveness trial. Gen Hosp Psychiatry 2006, 28:223-229.

2. Nieuwenhuijsen K, Bultmann U, Neumeyer-Gromen A, Verhoeven AC, Verbeek $\mathrm{JH}$, van der Feltz-Cornelis CM: Interventions to improve occupational health in depressed people. Cochrane Database Syst Rev 2008, 2:CD006237.

3. Rebergen DS, Bruinvels DJ, Bezemer PD, van $\operatorname{der}$ Beek AJ, van MW: Guideline-based care of common mental disorders by occupational physicians (CO-OP study): a randomized controlled trial. J Occup Environ Med 2009, 51:305-312.
4. Schene AH, Koeter MW, Kikkert MJ, Swinkels JA, McCrone P: Adjuvant occupational therapy for work-related major depression works: randomized trial including economic evaluation. Psychol Med 2007, 37:351-362.

5. Borg V, Andersen Nexø M, Kolte I, Andersen M: White book on mental health, sickness absence and return to work. [Hvidbog om mentalt helbred, sygefravær og tilbagevenden til arbejde]. Copenhagen: The National Research Centre for the Working Environment; 2010.

6. Statistics from the National Social Appeals Board: The National Social Appeals Board; Copenhagen 2013. http://ast.dk/tal-og-undersogelser/tal-fraankestyrelsen/.

7. Mental Illness and the Labour Market: Danske Regioner; Danske Regioner. Copenhagen, Denmark; 2009. Psykisk sygdom og arbejdsmarkedet.

8. Eplov LF, Korsbek L: Vocational rehabilitation for people with affective disorders or anxiety [Arbejdsmarkedsrettede indsatser for personer med affektive sindslidelser eller angstsygdomme]. The National Labour Market Authority; 2012.

9. Lexis MA, Jansen NW, Huibers MJ, van Amelsvoort LG, Berkouwer A, Tjin AT, van den Brandt PA, Kant I: Prevention of long-term sickness absence and major depression in high-risk employees: a randomised controlled trial. Occup Environ Med 2011, 68:400-407.

10. Wang PS, Simon GE, Avorn J, Azocar F, Ludman EJ, McCulloch J, Petukhova $M Z$, Kessler RC: Telephone screening, outreach, and care management for depressed workers and impact on clinical and work productivity outcomes: a randomized controlled trial. JAMA 2007, 298:1401-1411.

11. Wang PS, Simon GE, Kessler RC: Making the business case for enhanced depression care: the National Institute of Mental Health-Harvard Work Outcomes Research and Cost-effectiveness Study. J Occup Environ Med 2008, 50:468-475.

12. van der Feltz-Cornelis CM, Meeuwissen JA, de Jong FJ, Hoedeman R, Elfeddali I: Randomised controlled trial of a psychiatric consultation model for treatment of common mental disorder in the occupational health setting. BMC Health Serv Res 2007, 7:29.

13. van der Feltz-Cornelis CM, Hoedeman R, de Jong FJ, Meeuwissen JA, Drewes HW, van der Laan NC, Ader HJ: Faster return to work after psychiatric consultation for sicklisted employees with common mental disorders compared to care as usual. A randomized clinical trial. Neuropsychiatr Dis Treat 2010, 6:375-385.

14. Burns T, Catty J, Becker T, Drake RE, Fioritti A, Knapp M, Lauber C, Rossler W, Tomov T, van Busschbach J, White S, Wiersma D: The effectiveness of supported employment for people with severe mental illness: a randomised controlled trial. Lancet 2007, 370:1146-1152.

15. Bond GR, Drake RE, Becker DR: An update on randomized controlled trials of evidence-based supported employment. Psychiatr Rehabil J 2008, 31:280-290.

16. Drake R, Bond GR, Becker DR: Individual Placement and Support: An Evidence-Based Approach to Supported Employment. New York: Oxford University Press; 2012.

17. Cook JA, Leff HS, Blyler CR, Gold PB, Goldberg RW, Mueser KT, Toprac MG, McFarlane WR, Shafer MS, Blankertz LE, Dudek K, Razzano LA, Grey DD, Burke-Miller J: Results of a multisite randomized trial of supported employment interventions for individuals with severe mental illness. Arch Gen Psychiatry 2005, 62:505-512.

18. Gold PB, Meisler N, Santos AB, Carnemolla MA, Williams OH, Keleher J: Randomized trial of supported employment integrated with assertive community treatment for rural adults with severe mental illness. Schizophr Bull 2006, 32:378-395.

19. Hoffmann H, Jackel D, Glauser S, Kupper Z: A randomised controlled trial of the efficacy of supported employment. Acta Psychiatr Scand 2012, 125:157-167.

20. Killackey E, Jackson HJ, McGorry PD: Vocational intervention in first-episode psychosis: individual placement and support v. treatment as usual. Br J Psychiatry 2008, 193:114-120.

21. Kin WK, Chiu R, Tang B, Mak D, Liu J, Chiu SN: A randomized controlled trial of a supported employment program for persons with long-term mental illness in Hong Kong. Psychiatr Serv 2008, 59:84-90.

22. Latimer EA, Lecomte T, Becker DR, Drake RE, Duclos I, Piat M, Lahaie N, St-Pierre MS, Therrien C, Xie H: Generalisability of the individual placement and support model of supported employment: results of a Canadian randomised controlled trial. Br J Psychiatry 2006, 189:65-73.

23. Lehman AF, Goldberg R, Dixon LB, McNary S, Postrado L, Hackman A, McDonnell $K$ : Improving employment outcomes for persons with severe mental illnesses. Arch Gen Psychiatry 2002, 59:165-172. 
24. McGurk SR, Mueser KT, Pascaris A: Cognitive training and supported employment for persons with severe mental illness: one-year results from a randomized controlled trial. Schizophr Bull 2005, 31:898-909.

25. McGurk SR, Mueser KT, Feldman K, Wolfe R, Pascaris A: Cognitive training for supported employment: 2-3 year outcomes of a randomized controlled trial. Am J Psychiatry 2007, 164:437-441.

26. Tsang HW, Chan A, Wong A, Liberman RP: Vocational outcomes of an integrated supported employment program for individuals with persistent and severe mental illness. J Behav Ther Exp Psychiatry 2009, 40:292-305.

27. Twamley EW, Narvaez JM, Becker DR, Bartels SJ, Jeste DV: Supported employment for middle-aged and older people with schizophrenia. Am J Psychiatr Rehabil 2008, 11:76-89.

28. Campbell K, Bond GR, Drake RE: Who benefits from supported employment: a meta-analytic study. Schizophr Bull 2011, 37:370-380.

29. Bond GR, Salyers MP, Dincin J, Drake R, Becker DR, Fraser W, Haines M A randomized controlled trial comparing two vocational models for persons with severe mental illness. J Consult Clin Psychol 2007, 75:968-982.

30. Drake RE, McHugo GJ, Becker DR, Anthony WA, Clark RE: The New Hampshire study of supported employment for people with severe mental illness. J Consult Clin Psychol 1996, 64:391-399.

31. Drake RE, McHugo GJ, Bebout RR, Becker DR, Harris M, Bond GR, Quimby E: A randomized clinical trial of supported employment for inner-city patients with severe mental disorders. Arch Gen Psychiatry 1999, 56:627-633.

32. Mueser KT, Clark RE, Haines M, Drake RE, McHugo GJ, Bond GR, Essock SM, Becker DR, Wolfe R, Swain K: The Hartford study of supported employment for persons with severe mental illness. J Consult Clin Psychol 2004, 72:479-490.

33. The National Labour Market Authority in Denmark: The Match Model [Match model, Arbejdsmarkedsstyrelsen]. Copenhagen, Denmark: The National Labour Market Authority; 2013. https://www.retsinformation.dk/Forms/ R0710.aspx?id=139870.

34. Debts counselling, Settlementet: The Settlement. Copenhagen, Denmark; 2013. http://settlementet. dk/radgivning/gaeldsradgivning/.

35. Denmarks active labour market policy [Lov om en aktiv beskæftigelsesindssats]. Copenhagen, Denmark: Ministry of Employment; 2011. https://www. retsinformation.dk/Forms/R0710.aspx?id=128679.

36. Substance Abuse and Mental Health Services Administration: Supported Employment: Evaluating your Program, DHHS Pub. No. SMA-08-4364. Rockville, MD: Center for Mental Health Services, Substance Abuse and Mental Health Services Administration U.S. Department of Health and Human Services; 2009. http:/store.samhsa.gov/shin/content//SMA08-4365/EvaluatingYourProgram-SE.pdf.

37. Sheehan DV, Lecrubier $Y$, Sheehan KH, Amorim P, Janavs J, Weiller E, Hergueta T, Baker R, Dunbar GC: The Mini-International Neuropsychiatric Interview (M.I.N.I.): the development and validation of a structured diagnostic psychiatric interview for DSM-IV and ICD-10. J Clin Psychiatry 1998, 59(Suppl 20):22-33.

38. The National Labour Market Authority in Denmark: The DREAM database, Statistics Denmark [DREAM databasen, Danmarks Statistik]. Copenhagen, Denmark: The National Labour Market Authority; 2012. http://www.dst.dk/ da/TilSalg/Forskningsservice/Data/Andre Styrelser.aspx.

39. Bech P: Clinical psychometrics. Oxford: Wiley-Blackwell; 2012.

40. O'Sullivan RL, Fava M, Agustin C, Baer L, Rosenbaum JF: Sensitivity of the six-item Hamilton Depression Rating Scale. Acta Psychiatr Scand 1997, 95:379-384

41. Maier W, Buller R, Philipp M, Heuser I: The Hamilton Anxiety Scale: reliability, validity and sensitivity to change in anxiety and depressive disorders. J Affect Disord 1988, 14:61-68.

42. Pedersen G, Hagtvet KA, Karterud S: Generalizability studies of the Global Assessment of Functioning-Split version. Compr Psychiatry 2007, 48:88-94

43. Pedersen $G$, Karterud S: The symptom and function dimensions of the Global Assessment of Functioning (GAF) scale. Compr Psychiatry 2012, 53:292-298.

44. Licht RW, Jensen J: Validation of the Bech-Rafaelsen Mania Scale using latent structure analysis. Acta Psychiatr Scand 1997, 96:367-372.

45. Morosini PL, Magliano L, Brambilla L, Ugolini S, Pioli R: Development, reliability and acceptability of a new version of the DSM-IV Social and Occupational Functioning Assessment Scale (SOFAS) to assess routine social functioning. Acta Psychiatr Scand 2000, 101:323-329.

46. Nafees B, van Hanswijck de JP, Stull D, Pascoe K, Price M, Clarke A Turkington D: Reliability and validity of the Personal and Social Performance scale in patients with schizophrenia. Schizophr Res 2012, 140:71-76.

47. Sheehan DV, Harnett-Sheehan K, Raj BA: The measurement of disability. Int Clin Psychopharmacol 1996, 11:89-95.
48. Bech P, Licht RW, Stage KB: Rating scales for affective disorders [Rating scales for affektive lidelser]. Hillerød, Denmark: Psychiatric Research Unit CCMH, Mental Health Center Northern Zealand; 2005.

49. Rogers ES, Chamberlin J, Ellison ML, Crean T: A consumer-constructed scale to measure empowerment among users of mental health services. Psychiatr Serv 1997, 48:1042-1047.

50. Miller WR, Johnson WR: A natural language screening measure for motivation to change. Addict Behav 2008, 33:1177-1182.

51. Nguyen TD, Attkisson CC, Stegner BL: Assessment of patient satisfaction: development and refinement of a service evaluation questionnaire. Eval Program Plann 1983, 6:299-313.

52. Rabin R, de CF: EQ-5D: a measure of health status from the EuroQol Group. Ann Med 2001, 33:337-343.

53. Danish Psychiatric Case Register: [Psykiatrisk Centralregister]. Risskov, Denmark: Centre of Psychiatric research, University of Aarhus; 2013. http://tnu.dk/ psykiatrisk-centralregister/

54. Bartko JJ, Carpenter WT Jr: On the methods and theory of reliability. J Nerv Ment Dis 1976, 163:307-317.

55. Dupont WD, Plummer WD Jr: Power and sample size calculations: a review and computer program. Control Clin Trials 1990, 11:116-128.

56. Dupont WD, Plummer WD Jr: Power and sample size calculations for studies involving linear regression. Control Clin Trials 1998, 19:589-601.

57. Burns T, Catty J, White S, Becker T, Koletsi M, Fioritti A, Rossler W, Tomov T, van Busschbach J, Wiersma D, Lauber C: The impact of supported employment and working on clinical and social functioning: results of an international study of individual placement and support. Schizophr Bull 2009, 35:949-958.

58. Howard LM, Heslin M, Leese M, McCrone P, Rice C, Jarrett M, Spokes T: Huxley, P, Thornicroft, G: Supported employment: randomised controlled trial. Br J Psychiatry 2010, 196:404-411.

59. van Oostrom SH, van MW, Terluin B, de Vet HC, Knol DL, Anema JR: A workplace intervention for sick-listed employees with distress: results of a randomised controlled trial. Occup Environ Med 2010, 67:596-602.

60. Gueorguieva R, Krystal JH: Move over ANOVA: progress in analyzing repeated-measures data and its reflection in papers published in the Archives of General Psychiatry. Arch Gen Psychiatry 2004, 61:310-317.

61. The Psychiatric Central Research Register: First time contacts with mental health services [Førstegangskontakt med det psykiatriske sygehusvæsen]. Risskov, Denmark: Centre of Psychiatric research, University of Aarhus; 2013. http://tnu.dk/psykiatrisk-centralregister/aarstabeller/.

62. Burns T, Catty J: IPS in Europe: the EQOLISE trial. Psychiatr Rehabil J 2008, 31:313-317

63. McFarlane WR, Dushay RA, Deakins SM, Stastny P, Lukens EP, Toran J, Link B: Employment outcomes in family-aided assertive community treatment. Am J Orthopsychiatry 2000, 70:203-214.

\section{doi:10.1186/1745-6215-14-442}

Cite this article as: Hellström et al:: The effect of IPS-modified, an early intervention for people with mood and anxiety disorders: study protocol for a randomised clinical superiority trial. Trials 2013 14:442.

\section{Submit your next manuscript to BioMed Central and take full advantage of:}

- Convenient online submission

- Thorough peer review

- No space constraints or color figure charges

- Immediate publication on acceptance

- Inclusion in PubMed, CAS, Scopus and Google Scholar

- Research which is freely available for redistribution 